\title{
无过渡金属参与的异腈与芳基硼酸双插入偶联反应 高效构建双芳基甲胺衍生物
}

\author{
郑 龙王 鹏*
}

(中国科学院上海有机化学研究所 金属有机化学国家重点实验室 上海 200032)

\section{Efficient Synthesis of Diarylmethanamines via Transition-Metal-Free Double-Insertive Coupling of Isocyanides with Arylboronic Acids}

\author{
Zheng, Long Wang, Peng*
}

(State Key Laboratory of Organometallic Chemistry, Shanghai Institute of Organic Chemistry, Chinese Academy of Sciences, Shanghai 200032)

双芳基甲胺作为一类重要砌块广泛存在于生物活 性分子、药物载体和有机配体中(图 1), 因而对该类骨架 化合物的合成备受关注 ${ }^{[1]}$. 传统构建该类骨架的方法包 括羰基还原胺化 ${ }^{[2]}$ 、亲核取代和亚胺的亲核加成 ${ }^{[3]}$ 等, 然 而以上策略通常存在合成效率不高、底物范围受限等问 题. 近年来, 过渡金属催化的转移氢化 ${ }^{[4]}$ 和酰胺的还原 偶联反应 ${ }^{[5]}$ 相继被应用于双芳基甲胺类化合物的合成 中, 并取得一系列重要的研究成果. 鉴于药物合成中金 属残留问题, 发展无过渡金属参与的策略, 实现双芳基 甲基胺类化合物的构建仍十分必要. 近日, 华侨大学/福 州大学材料科学与工程学院宋秋玲课题组与南方科技 大学化学系余沛源课题组 ${ }^{[6]}$ 合作, 报道了异腈化合物和
芳基硼酸的双芳基迁移插入反应，实现了双芳基甲基胺 类化合物骨架的高效构建. 值得一提的是，该反应的反 应模式新颖，无需过渡金属参与，同时具有广谱的底物 范围和官能团兼容性.

异氰化合物可以通过胺、醇、羧酸和环氧丙烷等高 效合成，通常被用于多组分反应和过渡金属催化的插入 反应中. 受异氧化合物可以在强 Lewis 酸条件下被芳基 金属试剂双插入构建双芳基甲胺衍生物 ${ }^{[7]}$ 和异氰一硼 “ate”复合物 1,2-迁移的启发 ${ }^{[8]}$, 该研究团队提出使用异 氧和有机嗍试剂双芳基迁移插入反应构建双芳基甲胺 衍生物. 经过一系列的条件优化, 发现当使用 $\mathrm{K}_{3} \mathrm{PO}_{4}$ 作 碱, 三氟甲苯作溶剂, 可以高效地实现烷基或者芳基异<smiles>Cc1ncccc1C(C#N)N1CCN(C(=O)CNC(c2ccccc2)c2ccccc2)CC1</smiles>

PAF Antagonist

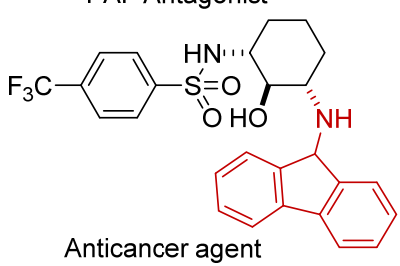

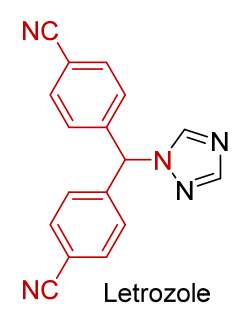

Ligand

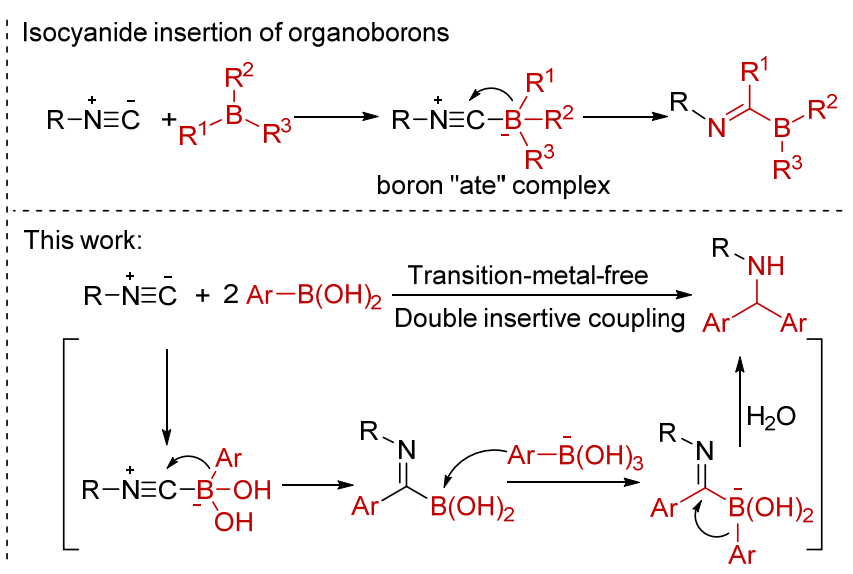

图 1 无过渡金属参与的异腈与芳基硼酸双插入偶联反应

Figure 1 Transition-metal-free double-insertive coupling of isocyanides with arylboronic acids

* Corresponding author. E-mail: pengwang@sioc.ac.cn. Published online March 8, 2021. 
腈化合物和芳基硼酸的插入偶联反应.

对底物普适性进行考察发现，该反应可以同时兼容 芳基和烷基异氰化合物, 用于构建 $N$-芳基或 $N$-烷基双 芳基甲胺衍生物. 当使用环状硼酐时, 可以实现重要药 物结构 9-芴胺骨架的高效合成. 无过渡金属参与的催化 模式也带来了对杂原子官能团优秀的兼容性(图 2).

为了体现该方法的实用性和应用价值, 作者将该策 略应用到 Fluoxetine, Nimodipine, Linagliptin 等生物活性 分子和药物分子的后期修饰中, 可以取得中等到良好的 收率, 为高效获得复杂分子衍生物用于生物活性篮选提
供了合成工具. 此外, 双芳基甲胺也可以应用于配体合 成中, 研究人员利用他们合成的目标化合物, 也合成了 基于手性联菜骨架的亚膦酰胺配体.

最后，通过实验和密度泛函理论计算，对该反应机 理进行了深入研究. 该团队认为当使用芳基硼酸作为反 应底物时，首先形成三喼酸酐中间体，随后异腈类化合 物对硼酸酐进行插入, 发生芳基迁移得到亚胺硼酸酐中 间体. 接着在碱的作用下，亚胺嗍酸酐中间体中的另一 部分芳基发生分子内的迁移插入，最终通过脱除硼酸质 子化得到目标产物(图 3).

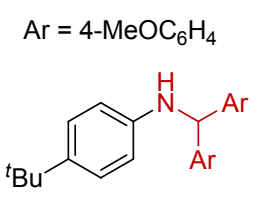

$84 \%$ yield<smiles>[Al]C([Al])NC12CC3CC(CC(C3)C1)C2</smiles>

$80 \%$ yield<smiles>[C]C([Al])Nc1ccc(C2(c3ccc(NC([Al])C4CCCCC4)cc3)CCCCC2)cc1</smiles>

$40 \%$ yield<smiles>BrC(Br)Nc1cccc2ncccc12</smiles>

$54 \%$ yield<smiles>BrC(Br)CNCCc1c[nH]c2ccccc12</smiles>

$23 \%$ yield<smiles>CC1(NC(Br)Br)CCN(C(=O)OC(C)(C)C)CC1</smiles>

$76 \%$ yield<smiles>COc1ccc(C(Nc2ccc(C)cc2)c2ccc(C)cc2)cc1</smiles>

$67 \%$ yield

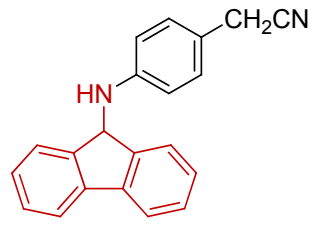

$88 \%$ yield

图 2 代表性双芳基甲胺产物

Figure 2 Representative diarylmethanamine products

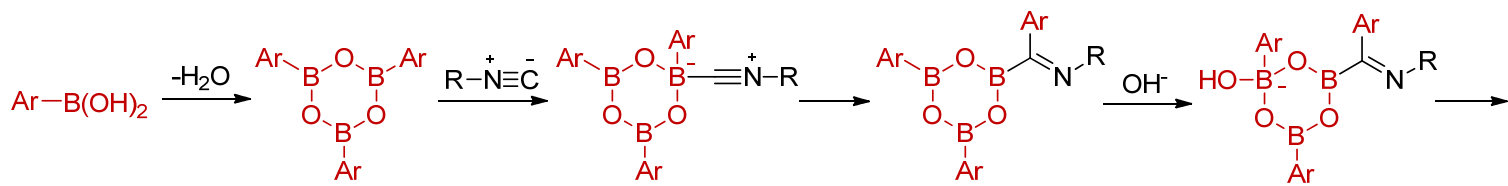

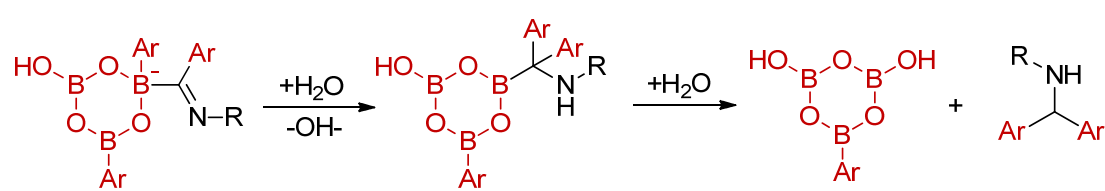

图 3 异腈类化合物和芳基硼酸偶联反应机理

Figure 3 Mechanism of the coupling of isocyanide with aryl boronic acid

\section{References}

[1] (a) Kato, M.; Komoda, K.; Namera, A.; Sakai, Y.; Okada, S.; Yamada, A.; Yokoyama, K.; Migita, E.; Minobe, Y.; Tani, T. Chem. Pharm. Bull. 1997, 45, 1767.

(b) Carceller, E.; Merlos, M.; Giral, M.; Almansa, C.; Bartrolí, J.; García-Rafanell, J.; Forn, J. J. Med. Chem.1993, 36, 2984.

[2] Abdel-Magid, A. F.; Carson, K. G.; Harris, B. D.; Maryanoff, C. A.; Shah, R. D. J. Org. Chem. 1996, 61, 3849.

[3] Murai, T.; Asai, F. J. Am. Chem. Soc. 2007, 129, 780.
[4] Guillena, G.; J Ramón, D.; Yus, M. Chem. Rev. 2010, 110, 1611.

[5] Xie, L.-G.; Dixon, D. J. Chem. Sci. 2017, 8, 7492.

[6] Yang, K.; Hu, X. X.; Li, W. Y.; Qiu, J.; Feng, Q.; Wang, S. H.; Zhang, G.; Kuang, Z. J.; Yu, P. Y.; Song, Q. L. Cell Rep. Phys. Sci. 2020, 1,100268 .

[7] Foschi, F.; Roth, T.; Wadepohl, H.; Gade, L. H. Org. Lett. 2016, 18, 5182.

[8] Suginome, M.; Fukuda, T.; Nakamura, H.; Ito, Y. Organometallics 2000, 19, 719 .

(Cheng, F.) 